\title{
CD4 positive/CD8 negative/CD56 positive T cell large granular lymphocyte proliferations; clonal disorders of uncertain significance
}

\author{
Deepti Mutreja, Rahul Kumar Sharma, Mrinalini Kotru and Renu Saxena*
}

\begin{abstract}
Background: Clonal expansions of CD4 positive T large granular lymphocytes with or without co-expression of CD8 are extremely uncommon. These typically display an indolent clinical course and are said to be associated with other solid malignancies. We present the clinicopathologic features and immunophenotypic analyses of two rare cases of CD4 positive T large granular lymphocyte proliferation with expression of natural killer cell associated antigen CD56. Both had high positive anti cytomegalovirus (CMV) IgG titres and persistent lymphocytosis with a relatively benign course at 15 and 13 months of follow up, respectively.

\section{Case presentation:}

Case 1

A 58 year old Indian man presented with fever and cough of one week duration. On examination, he was febrile with crackles in the right lower zone. Hematological investigations revealed mild neutropenia and a monotypic CD3 positive/CD4 positive/CD8 negative/CD56 positive/T cell receptor alpha-beta positive large granular lymphocyte population representing $50 \%$ of blood and bone marrow lymphocytes. Clonality was demonstrated using a T cell receptor gamma polymerase chain reaction. A chest roentgenogram showed features suggestive of bronchopneumonia. Patient was treated with broad spectrum antibiotics and antipyretics with improvement. At follow up of 15 months, he continued to have persistent large granular lymphocytosis.

Case 2

A 38 year old Indian woman presented with generalized weakness and malaise of two months duration. On examination, she was afebrile with no lympadenopathy or hepatosplenomegaly. A routine hemogram showed absolute lymphocytosis. Flow cytometric evaluation was performed on peripheral blood affirmed the cells to be CD4 positive T large granular lymphocytes, with similar findings to the first case. At follow up of 13 months, patient was otherwise asymptomatic but continued to have persistent CD4 positive large granular lymphocytosis.

Conclusions: Flow cytometric immunophenotyping remains an essential tool for the diagnosis of T cell proliferations and helped to clinch the diagnosis in these cases. The aim of this case series is to present clinical and immunophenotypic features of these rare CD4 positive T large granular lymphocyte proliferations that fulfil the WHO defining criteria, however are better regarded as clonal expansions rather than as leukemias in view of their indolent and non progressive nature.
\end{abstract}

\footnotetext{
* Correspondence: renusaxena@outlook.com

Department of Hematology, All India Institute of Medical Sciences, New Delhi, India
} 


\section{Background}

Large granular lymphocytes (LGL) comprise $10-15 \%$ of peripheral blood mononuclear cells with absolute counts in the range of $0.1-0.3 \times 10^{9} / \mathrm{L}$. These are characterized by high cytoplasmic: nuclear ratio and abundant azurophilic granules [1,2]. LGL include both cytotoxic T lymphocytes $\left(\mathrm{CD}^{+}\right)$and natural killer(NK) cells $\left(\mathrm{CD}^{-}\right)$, both of which serve as the main perpetrators of cell-mediated cytotoxicity [3]. There are three notable variants of T-LGL leukemia, based primarily on immunophenotypic differences. These are $\mathrm{CD} 4^{-} / \mathrm{CD} 8^{+}, \mathrm{CD} 4^{-} / \mathrm{CD}^{-}$or $\mathrm{CD}^{+} /$ $\mathrm{CD}^{-/+\operatorname{dim}}$ cells [4]. $\mathrm{CD}^{+} / \mathrm{CD}^{-} / \mathrm{CD}^{-} 6^{+} \mathrm{T}$-LGL proliferations are rare and reported sporadically in case reports $[5,6]$ and small case series $[7,8]$ in literature. These typically display an indolent clinical course and are said to be associated with other solid malignancies. There is no apparent association with rheumatoid arthritis or other autoimmune diseases in contrast to the more common $\mathrm{CD}^{+}$ T-LGL expansions [8].

It has been suggested that chronic antigenic stimulation of $\mathrm{T}$ cells by cytomegalovirus (CMV) can lead to persistent monoclonal expansions of $\mathrm{CD}^{+} / \mathrm{NK}$ antigen ${ }^{+} / \mathrm{CD}^{-/+\operatorname{dim}}$ lymphocytes in patients having a particular HLA subtype [9]. We report two cases of $\mathrm{CD}^{+} / \mathrm{CD}^{-} / \mathrm{CD}^{2} 6^{+} \mathrm{T}$-LGL proliferation that lacked hepatosplenomegaly and lymphadenopathy and had high positive anti cytomegalovirus (CMV) IgG titres.

\section{Case presentation \\ Case 1}

A 58 year old male presented with fever and cough of one week duration with associated generalized weakness, malaise and increased fatigue of three months duration. On examination he was febrile with temperature $100^{\circ} \mathrm{F}$. Chest examination revealed few crackles in the right lower zone. No organomegaly or lympadenopathy were seen. A routine hemogram showed hemoglobin of $14.8 \mathrm{~g} / \mathrm{dL}(13.5-$ $17 \mathrm{~g} / \mathrm{dL})$, leucocyte count of $26.88 \times 10^{9} / \mathrm{L}\left(4-11 \times 10^{9} / \mathrm{L}\right)$ and platelet count of $210 \times 10^{9} / \mathrm{L}\left(150-400 \times 10^{9} / \mathrm{L}\right)$. The absolute lymphocyte count was $23.65 \times 10^{9} / \mathrm{L}(1-3 \times$ $10^{9} / \mathrm{L}$ ) and absolute neutrophil count (ANC) was $1.34 \times$ $10^{9} / \mathrm{L}\left(2-7 \times 10^{9} / \mathrm{L}\right)$. Peripheral smear showed $90 \%$ mature lymphoid cells, with most (75\%) showing characteristic large granular lymphocytic morphology (Figure 1). Bone marrow (BM) aspirate smears were normocellular and showed increased mature lymphoid cells ( 45\%). BM biopsy sections showed normocellular marrow with subtle interstitial lymphoid cell infiltrates that were hardly discernible on morphology. Immunohistochemistry on bone marrow biopsy was not performed. A chest roentgenogram showed features suggestive of bronchopneumonia. Patient was seropositive for cytomegalovirus (CMV) IgG antibodies with high titres ( $>250 \mathrm{AU} / \mathrm{ml}$; non reactive $<6 \mathrm{AU} / \mathrm{ml}$ ). However, anti

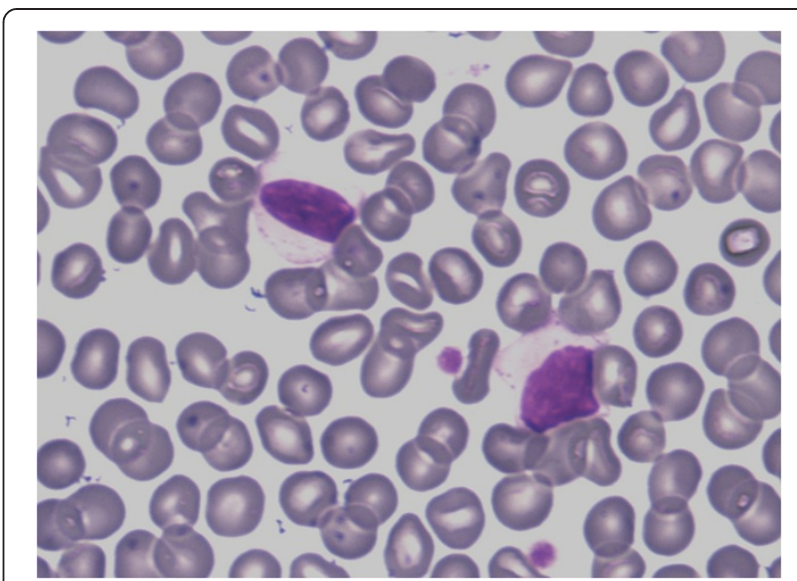

Figure 1 Peripheral smear. Peripheral smear showing large granular lymphocytes (Jenner Giemsa, 100x).

IgM CMV antibodies and serology for human immunodeficiency virus (HIV) and Ebstein Barr virus (EBV) were negative. Rheumatoid factor, antinuclear antibodies, direct and indirect Coomb's tests were negative.

Immunophenotyping was performed on BD FACS CantoTM flow cytometer and the analysis and interpretation were carried out post-acquisition by BD FACS Diva software (BD Biosciences, San Jose, CA). Fluorescence measurement was expressed as the percentage of positive cells above a threshold set against a similarly processed unstained tube acting as negative control. Flow cytometry on BM aspirate showed large lymphoid cluster of cells ( $\sim 50 \%$ of all cells) with bright CD45 positivity. The cells were of T-cell origin and showed bright positivity for CD3(99\%), CD5(94\%), CD2(99\%), CD4 (90\%), TCR $\alpha \beta(95 \%)$ and CD56(87\%) (Figure 2). CD7 expression was dim to weak seen in less than $20 \%$ cells. CD8 expression and T cell receptor(TCR) $\gamma \delta$ were negative. Other B lymphoid cell markers including CD10, CD19, CD23, CD20, CD22, CD38, CD79b, CD103 and $\mathrm{CD} 11 \mathrm{c}$ and were negative. Monoclonal TCR $\gamma$ chain gene rearrangement was demonstrated by polymerase chain reaction (PCR) amplification of genomic DNA. In view of morphology, immunophenotypic findings and monoclonality, a diagnosis of $\mathrm{CD} 4^{+} / \mathrm{CD}^{-} / \mathrm{CD} 56^{+} \mathrm{T}-\mathrm{LGL}$ leukemia was established. Patient was treated with broad spectrum antibiotics and antipyretics with improvement. On follow up at 15 months patient was asymptomatic with persistent lymphocytosis in the range of $12-19 \times 10^{9} / \mathrm{L}$.

\section{Case 2}

A 38 year old female presented with generalized weakness and malaise of two months duration. On examination she was afebrile with no lympadenopathy or hepatosplenomegaly. A routine hemogram showed hb of $12.4 \mathrm{~g} / \mathrm{dL}(12-$ $15.3 \mathrm{~g} / \mathrm{dL})$, leucocyte count of $20.66 \times 10^{9} / \mathrm{L}\left(4-11 \times 10^{9} / \mathrm{L}\right)$ 

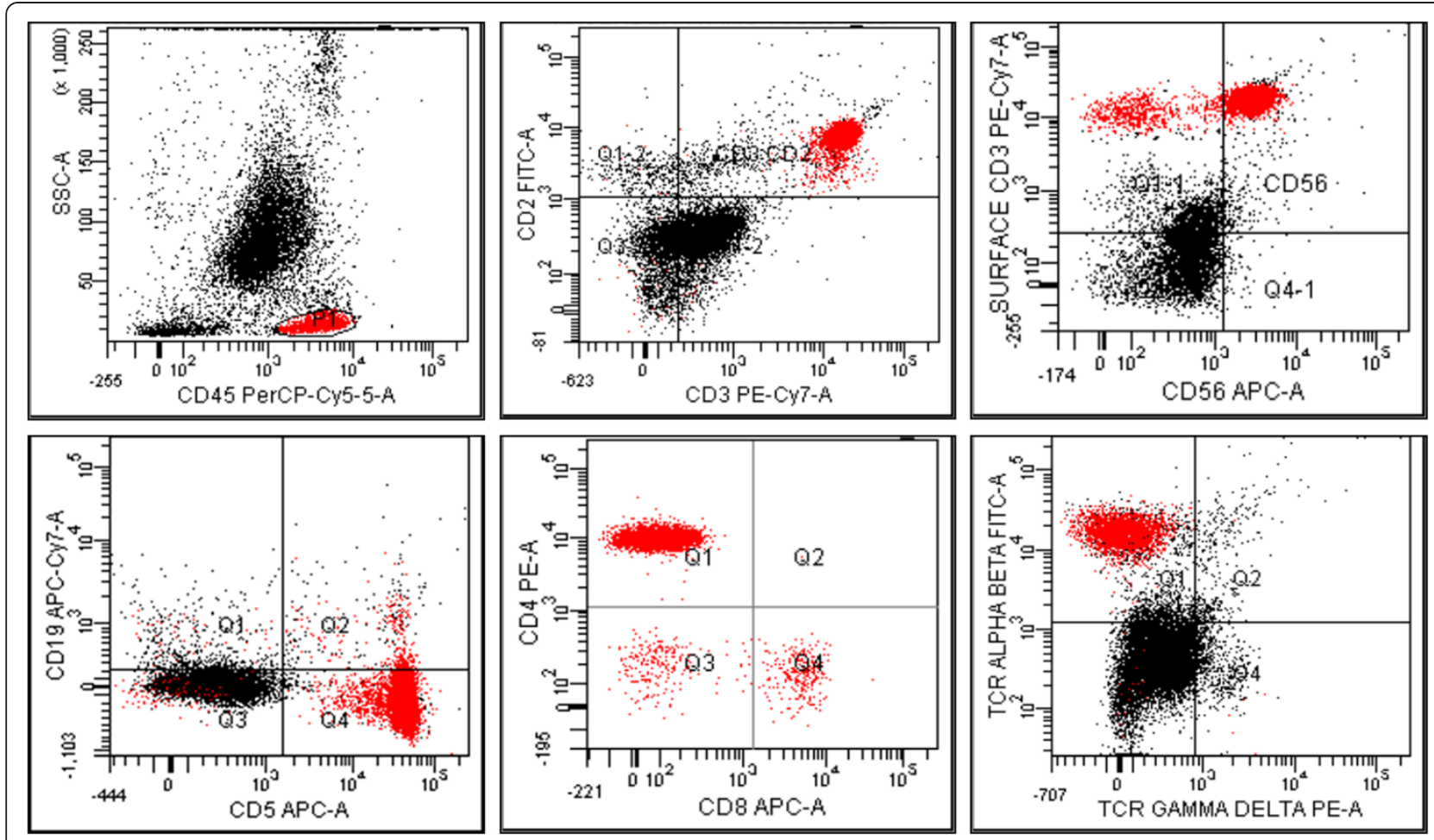

Figure 2 Case 1. Flow cytometric immunophenotyping of bone marrow. Flow Cytometric Immunophenotyping of bone marrow aspirate showing lymphocytes (red) expressing bright CD3(99\%), CD4(90\%), CD2(99\%), CD5(94\%), CD56(87\%), TCRaß(95\%) and lack CD8, CD19, and TCRy .

and platelet count of $235 \times 10^{9} / \mathrm{L}\left(150-400 \times 10^{9} / \mathrm{L}\right)$. Peripheral smear showed normocytic normochromic red cells, lymphocytes $78 \%$, with predominantly LGL morphology, neutrophils $18 \%$, monocytes $3 \%$ and eosinophil $1 \%$. Flow cytometric evaluation was performed on peripheral blood affirmed the cells to be $\mathrm{CD} 4^{+} / \mathrm{CD}^{-} / \mathrm{CD}^{2} 6^{+} \mathrm{T}$-LGLs, with similar findings to the first case. Akin to the first case, CD7 expression was variable (dim to negative), seen in around $30 \%$ cells. Monoclonality was ascertained on TCR gene rearrangements by PCR. Erythrocyte sedimentation rate, Creactive protein and lactate dehydrogenase were within normal limits. Rheumatoid factor and a panel of autoimmune markers (antinuclear antibodies, anti doublestranded desoxyribonucleic acid antibodies, SSA, SSB, Sm, RNP, Scl-70 and Jo-1) were negative. Similar to the first patient, anti CMV IgG antibodies were positive with high titres ( $>250 \mathrm{AU} / \mathrm{ml}$; non reactive $<6 \mathrm{AU} / \mathrm{L})$ ). CMV IgM, HIV and EBV serology were negative. A BM evaluation was not performed. At follow up of 13 months, patient was otherwise asymptomatic but continued to have persistent lymphocytosis in the range of $13-18 \times$ $10^{9} / \mathrm{L}$ with LGL morphology and similar immunophenotypic profile on repeat flow cytometry.

\section{Discussion}

The evidence of a peripheral blood LGL counts greater than $2 \times 10^{9} / \mathrm{L}$ lasting for more than six months is currently regarded as the criteria to define the disease. The World Health Organization (WHO) 2008 classification segregates T-LGL leukemia from aggressive NK cell leukemia and categorizes it in the subgroup of mature peripheral T-cell neoplasms [10]. Immunophenotypically, CD4 ${ }^{+}$T-LGL leukemia is a clonal expansion of granular lymphocytes that co-express CD56 and CD57 NKassociated antigens and variable levels of CD8 (CD8 $\left.{ }^{-/+} \mathrm{dim}\right)$ [8]. It is different from typical $\mathrm{CD}^{+}{ }^{+} \mathrm{T}-\mathrm{LGL}$ leukemia as most patients have normal findings on physical examination, with an indolent course. These patients lack neutropenia, anemia, and splenomegaly and an association with autoimmune disorders in contrast with most $\mathrm{CD}^{+} \mathrm{T}$ LGL leukemias [6-8].

Both patients in this report had $\mathrm{CD}^{+} / \mathrm{CD}^{-} / \mathrm{CD}^{-} 6^{+}$ T-LGL proliferation. CD7 expression was dim to negative in both cases. In a similar series of seven of eight cases showed CD7 underexpression [7]. Thus, CD7 underexpression could be regarded as a frequent aberrancy in $\mathrm{CD}^{+} / \mathrm{CD}^{-} / \mathrm{CD} 6^{+} \mathrm{T}$-LGL proliferation. The first patient in this report had an episode of mild neutropenia $\left(\mathrm{ANC}<1.5 \times 10^{9} / \mathrm{L}\right)$ at presentation associated with chest infection, however, the second patient was asymptomatic, but for non specific complaints of malaise and bodyache.

Some studies have suggested that activated $\mathrm{CD}_{4}^{+}$/ $\mathrm{CD}^{-/+}$dim/NK antigen ${ }^{+}$T-LGL proliferations are effort of the immune system to control tumor growth and are 
marked by their association with malignant diseases [8]. The associated neoplasia may appear after months to years after the initial diagnosis, hence, it is vital to perform an extensive assessment for cancer and a close follow-up of these patients. Both our patients had persistent large granular lymphocytosis but showed no evidence of any associated systemic malignancy at the end of 15 and 13 months of follow up respectively. A longer follow up may be required to ascertain this association.

Benign, reactive increases in LGLs are seen in association with a variety of causes, including post-splenectomy, allografts and chronic viral infections notably CMV $[9,10]$. Studies have shown that CMV seropositive immunocompetent healthy adults have oligoclonal expansions of CMV specific $\mathrm{CD}_{4}^{+} /$cytotoxic/memory $\mathrm{T}$ cells in the peripheral blood thus providing evidence for involvement of CMV in the ontogeny of $\mathrm{CD}^{+}$T-LGL [11]. Indian adult population has a high seroprevalence of $\mathrm{CMV}$ as reported in healthy blood donors ( 95\%) [12,13]. Hence, the association of seropositivity for CMV with LGL proliferation in our patients may be an occurrence by chance. Nevertheless, it cannot be ignored completely as both the patients had very high anti CMV IgG titres and it is possible that a latent CMV viral infection may have been responsible for chronic immune activation and inflammation leading to clonal expansion of $\mathrm{CD}^{+}$T-LGLs. This needs to be substantiated in larger studies on Indian population. Both our patients have not been subjected to any further treatment so far and are on close hematological and clinical follow up to determine whether therapeutic intervention will be necessary in future.

\section{Conclusion}

The aim of this case series is to present clinical and immunophenotypic features of rare CD4 positive T-LGL proliferations. Although these fulfil the WHO defining criteria, we prefer to refer to them as clonal expansions rather than as leukemias in view of their indolent and non progressive nature, to avoid causing undue panic to the patient. Flow cytometric immunophenotyping remains an essential tool for the diagnosis.

\section{Consent}

Written informed consent was obtained from the patient for publication of this case report and any accompanying images. A copy of the written consent is available for review by the Editor of this journal.

\footnotetext{
Abbreviations

LGL: Large granular lymphocytes; NK: Natural killer; CMV: Cytomegalovirus; BM: Bone marrow; ANC: Absolute neutrophil count, TCR: T cell receptor; aß: Alpha beta; $\gamma \delta$ : Gamma delta; hb: Hemoglobin; WHO: World Health Organization.
}

\section{Competing interests}

The authors declare that they have no competing interests.

\section{Authors' contributions}

DM, MK and RS analyzed and interpreted the patient data regarding the hematological disease. RKS performed the flow cytometric evaluation, and was a major contributor in writing the manuscript. All authors read and approved the final manuscript.

Received: 28 November 2013 Accepted: 20 June 2014 Published: 2 July 2014

\section{References}

1. O'Malley DP: T-cell large granular leukemia and related proliferations. Am J Clin Pathol 2007, 127(6):850-859.

2. Loughran TP Jr: Clonal diseases of large granular lymphocytes. Blood 1993, 82(1):1-14

3. Zhang D, Loughran TP Jr: Large granular lymphocytic leukemia: molecular pathogenesis, clinical manifestations, and treatment. Hematology Am Soc Hematol Educ Program 2012, 2012:652-659.

4. Lamy T, Loughran TP Jr: Clinical features of large granular lymphocyte leukemia. Semin Hematol 2003, 40(3):185-195.

5. Richards SJ, Sivakumaran M, Parapia LA, Balfour I, Norfolk DR, Kaeda J, Scott CS: A distinct large granular lymphocyte (LGL)/NK-associated (NKa) abnormality characterized by membrane CD4 and CD8 coexpression. The Yorkshire Leukaemia Group. Br J Haematol 1992, 82(3):494-501.

6. Dadu T, Rangan A, Bhargava M: CD4 + /NKa + /CD8(dim+) T-cell large granular lymphocytic leukemia: a rare entity. J Postgrad Med 2010, 56(3):223-224.

7. Olteanu H, Karandikar NJ, Eshoa C, Kroft SH: Laboratory findings in CD4(+) large granular lymphocytoses. Int J Lab Hematol 2010, 32(1 Pt 1):e9-e16.

8. Lima M, Almeida J, Dos Anjos Teixeira M, Alguero Md M del C, Santos AH, Balanzategui A, Queirós ML, Bárcena P, Izarra A, Fonseca S, Bueno C, Justiça B, Gonzalez M, San Miguel JF, Orfao A: TCRalphabeta+/CD4+ large granular lymphocytosis: a new clonal T-cell lymphoproliferative disorder. Am J Pathol 2003, 163(2):763-771

9. Richards SJ: A "pathogenetic" role for CMV in CD4+ LGL proliferations. Blood 2008, 112(12):4367-4368.

10. Chan WC, Foucar K, Morice WG, Catovskv D: T-cell large granular lymphocytic leukaemia. In WHO Classification of Tumours of Haematopoietic and Lymphoid Tissues. 4th edition. Edited by Swerdlow SH. Lyon: IARC Press; 2008:272-273.

11. Koskela HLM, Eldfors S, Ellonen P, van Adrichem AJ, Kuusanmäki H, Andersson El, Lagström S, Clemente MJ, Olson T, Jalkanen SE, Majumder MM, Almusa H, Edgren H, Lepistö M, Mattila P, Guinta K, Koistinen P, Kuittinen T, Penttinen K, Parsons A, Knowles J, Saarela J, Wennerberg K, Kallioniemi O, Porkka K, Loughran TP Jr, Heckman CA, Maciejewski JP, Mustjoki S: Somatic STAT3 mutations in large granular lymphocytic leukemia. N Engl J Med 2012, 366(20):1905-1913.

12. Rodríguez-Caballero A, García-Montero AC, Bárcena P, Almeida J, Ruiz-Cabello F, Tabernero MD, Garrido P, Muñoz-Criado S, Sandberg Y, Langerak AW, González M, Balanzategui A, Orfao A: Expanded cells in monoclonal TCR-alphabeta+/CD4+/NKa+/CD8-/+dim T-LGL lymphocytosis recognize hCMV antigens. Blood 2008, 112(12):4609-4616.

13. Kothari A, Ramachandran VG, Gupta P, Singh B, Talwar V: Seroprevalence of cytomegalovirus among voluntary blood donors in Delhi, India. J Health Popul Nutr 2002, 20(4):348-351.

doi:10.1186/2052-1839-14-9

Cite this article as: Mutreja et al:: CD4 positive/CD8 negative/CD56 positive T cell large granular lymphocyte proliferations; clonal disorders of uncertain significance. BMC Hematology 2014 14:9. 